\title{
Diagnosis of diabetes mellitus on the basis of HbA1c: Is this true in hypothyroidism also?
}

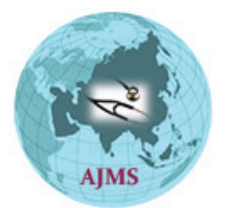

\author{
Abhishek Singhai', Prakhar Kabra² \\ ${ }^{1}$ Associate Professor, ${ }^{2}$ Postgraduate Student, Department of Medicine, Sri Aurobindo Medical College, Indore, \\ Madhya Pradesh, India
}

Background: Hypothyroidism may leads to hypoproliferative anemia. It is possible that this reduced erythropoiesis might result to false elevation of $\mathrm{HbA} 1 \mathrm{c}$ in some cases and further leading to an erroneous diagnosis of pre diabetes or diabetes. Aims and Objectives: This study was designed to assess changes in $\mathrm{HbA} 1 \mathrm{c}$ after initiation of thyroxine replacement in patients with subclinical and overt hypothyroidism. Settings and Design: This prospective study was conducted at Department of General Medicine of a tertiary care centre over one year. Materials and Methods: One-hundred subjects were recruited for the study. Fasting blood glucose, serum creatinine, hemoglobin, $\mathrm{HbA} 1 \mathrm{c}$, reticulocyte count, serum free T4 and TSH estimation done in all subjects. Hypothyroid patients were started on thyroxine. After three months of documentation of euthyroidism, same investigations were repeated.Statistical Analysis Used: Statistical software, SPSS version 17.0 was used for analysis. Results: After correction of hypothyroidism, TSH decreased from $92.3( \pm 30.9)$ to $3.4 \pm 2.9 \mu \mathrm{lU} / \mathrm{L}$ in overt hypothyroidism and from $12.2( \pm 4.5)$ to $4.4 \pm 2.9 \mu \mathrm{lU} / \mathrm{ml}$ in subclinical hypothyroidism respectively. There was a statistically significant fall in the $\mathrm{HbA} 1 \mathrm{c}(\mathrm{SD})$ from $5.9 \%(0.8)$ to $5.6 \%(0.6)$ and $6.0 \%(0.3)$ to $5.7 \%(0.3)$ following the correction of hypothyroidism in overt hypothyroidism and subclinical hypothyroidism respectively. However, there were no statistically significant changes in the fasting as well as postprandial blood glucose. Conclusions: Our study demonstrated that $\mathrm{HbA} 1 \mathrm{c}$ values are falsely increased in patients with hypothyroidism. This falsely raised $\mathrm{HbA} 1 \mathrm{c}$ became normal after thyroxine supplement.

Key words: Hypothyroidism, Anemia, Glycosylated haemoglobin, Euthyroidism, Reticulocyte count

\section{INTRODUCTION}

Glycosylated hemoglobin (HbA1C) is commonly used for diagnosing diabetes mellitus as well as assessment of glycemic status of the diabetic patients. A value $\geq$ $6.5 \%$ is considered diagnostic of diabetes mellitus while value $\geq 5.7 \%$ but $<6.5 \%$ was considered to represent pre-diabetes. ${ }^{1,2}$ Conditions that are associated with decreased red blood cells (RBC) production, with a predominance of older RBCs in circulation are associated with a falsely elevated HbA1c. Hypothyroidism may lead to either microcytic hypochromic anemia, normocytic normochromic or macrocytic anemia., ${ }^{3,4}$ The etiology of anemia in hypothyroidism can be related to the nutritional iron deficiency or to the endocrine disorder itself where the lowered thyroid hormone levels often results in decreased erythrocyte production which may affect the life span of erythrocytes. It is possible that this reduced erythropoiesis might results in false elevation of HbA1c in some cases and further leading to an erroneous diagnosis of pre diabetes or diabetes. ${ }^{5}$ Hence this study was designed to evaluate the changes in $\mathrm{HbA} 1 \mathrm{c}$ after initiation of thyroxine replacement in patients with subclinical and overt hypothyroidism.

\section{MATERIALS AND METHODS}

\section{Study design}

This is a prospective study. 


\section{Study setup}

This study is conducted at Department of General Medicine of a tertiary care centre.

\section{Study duration}

The duration of study was one year; November-2014 to October-2015.

\section{Sampling}

Purposive sampling technique is used for selection of desired samples according to inclusion criterion.

\section{Sample size}

One thousand patients of general medicine department of a tertiary care centre were evaluated for possible inclusion in study. Out of these 100 subjects were recruited for the study after fulfilling inclusion criteria.

\section{Inclusion criteria}

All adults with symptoms of hypothyroidism with thyroid stimulating hormone $(\mathrm{TSH})>5.5 \mu \mathrm{IU} / \mathrm{mL}$ were included in this study.

\section{Exclusion criteria}

Patients with history of diabetes mellitus, chronic kidney disease, hemolytic anemia, bone marrow suppression or blood transfusion in last 3 months were excluded from the study.

\section{METHODS}

Demographic characters like age, sex, height, weight of all subjects were noted. Fasting blood glucose (FBG), serum creatinine, hemoglobin $(\mathrm{Hb}), \mathrm{HbA1c}$, reticulocyte count, serum free T4 and TSH estimation was done in all participants. Patients were classified into three groups based on $\mathrm{HbA1c}$ as per ADA guidelines. Patients were labelled as euglycemia (HbA1c < 5.7\%), prediabetes (HbA1c 5.7-6.5) and diabetes mellitus (HbA1c $\geq 6.5 \%$ ). Blood sample for blood glucose was collected again 2 hours after breakfast. Patients with fasting blood glucose $(\mathrm{FBG}) \geq 110$ but $<$ $126 \mathrm{mg} / \mathrm{dl}$ were labelled as having impaired fasting glucose (IFG), while those with 2 hrs postmeal blood glucose (PBG) $\geq 140 \mathrm{mg} / \mathrm{dl}$ but $<200 \mathrm{mg} / \mathrm{dl}$ were labelled having impaired glucose tolerance (IGT). Prediabetics had either IFG or IGT or both. Patients with FPG $\geq 126 \mathrm{mg} / \mathrm{dl}$ or $\mathrm{PBG} \geq 200 \mathrm{mg} / \mathrm{dl}$ were excluded from the study.

The diagnosis of hypothyroidism was based on clinical grounds, biochemically on suppressed levels of free Thyroxine T4 (58-161 nmol/L) and increased TSH (> $5.5 \mu \mathrm{IU} / \mathrm{L})$ using immune assay.

Patients were started on thyroxine supplements in the dose of 25-50 mcg. The dose of the drug increased every
6 weeks step wise, based on TSH estimations till the patients were rendered euthyroid (TSH 0.3-5.5 $\mu \mathrm{IU} / \mathrm{ml}$ ). After three months of documentation of euthyroidism, all investigations as done before were repeated.

\section{Ethical consideration}

Prior to conduct of the present study, the protocol of the study was submitted to ethical and scientific committee of hospital. After getting due approval from these two committees, the present study was initiated. Also prior to conduct of study related procedure/investigation, a voluntary written informed consent was taken from the patient/legally acceptable representative.

\section{Statistical technique}

The demographic data of 100 subjects was analysed by statistical software, SPSS version 17.0. Continuous variables were compared with same parameters measured 3 months after the restoration of euthyroidism using two tailed paired $t$ test with a $\mathrm{p}$ value of $<0.05$ being considered as significant.

\section{Financial input and funding}

The patient underwent procedures as per protocol laid down by our institution for management of such patients. Hence there was no financial burden on patient or institution. This project was not funded by any of pharmaceutical/diagnostic industry.

\section{RESULTS}

A total of 100 subjects with symptoms of hypothyroidism with TSH $>5.5 \mu \mathrm{IU} / \mathrm{mL}$ were recruited for the study over a period of one year. Baseline patient characteristics are given below in Table 1.

Mean age (SD) of overt hypothyroid and subclinical hypothyroidism subjects was 40.2 (9.8) and 46.6 (10.8) years respectively. Female preponderance was seen in both groups. Baseline BMI was 28.5 and 25.7 in overt hypothyroidism and subclinical hypothyroidism subjects respectively. After treatment with thyroxine, BMI decreased in both groups. Serum creatinine was normal in all subjects and it remained same after treatment also. Free T4 was low in overt hypothyroidism and it increased significantly after treatment while in subclinical hypothyroidism, free T4 was within normal limits before and after treatment. After correction of hypothyroidism, TSH decreased from $92.3( \pm 30.9)$ to $3.4 \pm 2.9 \mu \mathrm{IU} / \mathrm{L}$ and $12.2( \pm 4.5)$ to $4.4 \pm 2.9 \mu \mathrm{IU} / \mathrm{ml}$ in overt hypothyroidism and subclinical hypothyroidism respectively. Hemoglobin and reticulocyte count was normal before and after treatment in both groups. 


\begin{tabular}{|c|c|c|c|c|c|c|}
\hline \multirow[t]{2}{*}{ Parameters } & \multicolumn{3}{|c|}{ Overt hypothyroidism } & \multicolumn{3}{|c|}{ Subclinical hypothyroidism } \\
\hline & Pre-therapy & Post-therapy & $p$ value & Pre-therapy & Post-therapy & p value \\
\hline Age (years) & $40.2 \pm 9.8$ & & - & $46.6 \pm 10.8$ & & - \\
\hline Sex (F:M Ratio) & $27: 3$ & & - & $60: 10$ & & - \\
\hline BMI $\left(\mathrm{kg} / \mathrm{m}^{2}\right)$ & $28.5 \pm 3.2$ & $27.2 \pm 2.2$ & NS & $25.7 \pm 1.8$ & $24.4 \pm 1.1$ & NS \\
\hline Serum creatinine $(\mathrm{mg} / \mathrm{dl})$ & $0.78 \pm 0.2$ & $0.77 \pm 0.18$ & NS & $0.79 \pm 0.19$ & $0.80 \pm 0.20$ & NS \\
\hline Free T4 (nmol/L) & $38 \pm 12.8$ & $90.2 \pm 20.1$ & $p<0.005$ & $78.1 \pm 16.4$ & $100 \pm 11.4$ & $p<0.005$ \\
\hline TSH $(\mu \mathrm{IU} / \mathrm{L})$ & $92.3 \pm 30.9$ & $3.4 \pm 2.9$ & $p<0.005$ & $12.2 \pm 4.5$ & $4.4 \pm 2.9$ & $p<0.005$ \\
\hline $\mathrm{Hb}(\mathrm{gm} / \mathrm{dl})$ & $12.1 \pm 1.2$ & $12.2 \pm 1.1$ & NS & $11.9 \pm 2.6$ & $11.8 \pm 2.9$ & NS \\
\hline Reticulocyte count (\%) & $1.4 \pm 0.1$ & $1.3 \pm 0.2$ & NS & $1.2 \pm 0.2$ & $1.1 \pm 0.4$ & NS \\
\hline FBG (mg/dl) & $85.4 \pm 12.4$ & $86.3 \pm 11.3$ & NS & $88.2 \pm 10.7$ & $90.1 \pm 9.9$ & NS \\
\hline PBG (mg/dl) & $121 \pm 14.5$ & $120 \pm 11.9$ & NS & $122.7 \pm 12.8$ & $121.7 \pm 9.9$ & NS \\
\hline $\mathrm{HbA} 1 \mathrm{c}(\%)$ & $5.9 \pm 0.8$ & $5.6 \pm 0.6$ & $p=0.04$ & $6.0 \pm 0.3$ & $5.7 \pm 0.3$ & $p=0.04$ \\
\hline
\end{tabular}

There was a statistically significant fall in the HbA1c (SD) from $5.9 \%(0.8)$ to $5.6 \%(0.6)$ and $6.0 \%(0.3)$ to $5.7 \%(0.3)$ following the correction of hypothyroidism in overt hypothyroidism and subclinical hypothyroidism respectively. However, there were no statistically significant changes in the fasting and the $2 \mathrm{hr}$ post postprandial blood glucose.

\section{DISCUSSION}

HbA1c has been recommended for the diagnosis of diabetes mellitus by American Diabetes Association. ${ }^{6}$ However, HbA1c use remained controversial in certain conditions, where RBC turnover is low. In these conditions $\mathrm{HbA1c}$ does not accurately reflect sugar levels. Thus disorders with decreased RBC lifespan and dominance of older RBCs in circulation, like iron deficiency anemia, ${ }^{7,8}$ megaloblastic anemia, ${ }^{7}$ or chronic renal failure, ${ }^{9}$ can have a falsely elevated $\mathrm{HbA1c}$.

We enrolled newly diagnosed patients with overt and subclinical hypothyroidism. Those patients with FBG or PBG in the diabetic range (i.e FPG $\geq 126 \mathrm{mg} / \mathrm{dl}$ and PBG $\geq 200 \mathrm{mg} / \mathrm{dl}$ ) were excluded from the study as they would require oral hypoglycemic drugs immediately. These oral hypoglycemic drugs will also lower $\mathrm{HbA1c}$ and thus we will unable to see effect of thyroxine on $\mathrm{HbA1c}$. Only patients with normal glucose values were thus included. Despite the mean FPG and PBG being normal, the mean HbA1c at baseline was already in the prediabetes range. Therefore in hypothyroidism there is a very high false positive rate for the diagnosis of diabetes mellitus, if $\mathrm{HbA} 1 \mathrm{c}$ alone is used as the diagnostic test. This false elevation of HbA1c was also demonstrated by Kim et al., ${ }^{10}$ who showed that HbA1c in 45 hypothyroid patients was higher than that in control subjects $(5.54 \pm 0.43 \%$ vs. $5.34 \pm 0.31 \%$ in hypothyroid patients and controls respectively; $\mathrm{p}<0.001$ ), despite the lower level of plasma fasting glucose in the hypothyroid individuals.
Another study by Christy et al selected 30 hypothyroid, non diabetic patients with normocytic normochromic anemia and compared these patients with 30 euthyroid non diabetic patients also with normocytic normochromic anemia. HbA1c in the hypothyroid patients was $6.32 \pm 0.75 \%$ vs. $5.87 \pm 0.46 \%$ in the euthyroid group, the difference being statistically significant. ${ }^{11}$ The correlation which was seen in this study was also shown by another study which significantly correlated TSH and HbA1c ( $\mathrm{r}=0.46$, $\mathrm{p}<0.05) .^{12}$

Anantarapu et al. ${ }^{13}$ showed the comparison between the HbA1c, FBG and PBG at baseline and at 3 months after the correction of hypothyroidism. While there was a fall in the HbA1c from $5.8 \pm 0.7 \%$ to $5.6 \pm 0.5 \%(p=0.009)$ following the treatment of hypothyroidism, there were no corresponding changes in the FBG and PBG.

After achieving euthyroidism for at least 3 months, HbA1c decreased to a normal value, despite there being no change in the FBG and the PBG. Similar findings were also reported by Kim et al. ${ }^{10}$ in their 30 hypothyroid patients who were reported to have normal HbA1c after thyroxin replacement.

Though there was a mean fall in BMI of approximately $1.3 \mathrm{~kg} / \mathrm{m}^{2}$ from baseline following the treatment of hypothyroidism, the blood glucose values remained unchanged. Decrease in the HbA1c cannot be attributed to the fall in the BMI. Because only mechanism by which BMI can affect $\mathrm{HbA1c}$ is through the level of sugar, which has remained unaffected between baseline and post therapy in our study.

\section{CONCLUSION}

Our study demonstrated that HbA1c values are falsely increased in patients with hypothyroidism. This falsely raised $\mathrm{HbA} 1 \mathrm{c}$ became normal after thyroxine supplement. 
Therefore in hypothyroid patients, diagnosis of diabetes mellitus should be done after fulfilling fasting sugar, postprandial sugar and oral glucose tolerance test criteria.

\section{REFERENCES}

1. Expert Committee on the Diagnosis and Classification of Diabetes Mellitus. Report of the Expert Committee on the Diagnosis and Classification of Diabetes Mellitus. Diabetes Care 1997;20:1183-1197.

2. Genuth S, Alberti KG, Bennett P, Buse J, Defronzo R, Kahn R, et al. The Expert Committee on the Diagnosis and Classification of Diabetes Mellitus. Follow-up report on the diagnosis of diabetes mellitus. Diabetes Care 2003; 26:3160-167.

3. Rafat D, Rabbani TK, Ahmad J and Ansari MA. Influence of iron metabolism indices on $\mathrm{HbA} 1 \mathrm{c}$ in non-diabetic pregnant women with and without iron-deficiency anemia: effect of iron supplementation. Diabetes \& Metabolic Syndrome: Clinical Research and Reviews 2012; 6:102-105.

4. Tarim O, Küçükerdoğan A, Günay U, Eralp $O$ and Ercan I. Effects of iron deficiency anemia on hemoglobin $\mathrm{A} 1 \mathrm{c}$ in type 1 diabetes mellitus. Pediatrics International 1999; 41:357-1362.

5. Mortensen HB, Vølund A and Christophersen C. Glucosylation of human haemoglobin A. Dynamic variation in $\mathrm{HbA} 1 \mathrm{c}$ described by a biokinetic model. Clinical Chimica Acta 1984; 136:75-81.
6. American Diabetes Association. Diagnosis and classification of diabetes mellitus. Diabetes Care. 2010; 33:62-69.

7. Gram-Hansen P, Eriksen J, Mourits-Andersen $T$ and Olesen L. Glycosylated Haemoglobin (HbA1c) in iron- and vitamin B12 deficiency. Journal of Internal Medicine 1990; 227:133-136.

8. Coban E, Ozdogan $M$ and Timuragaoglu A. Effect of iron deficiency anemia on the levels of hemoglobin $\mathrm{A} 1 \mathrm{C}$ in nondiabetic patients. Acta Haematologica 2004; 112:126-128.

9. $\mathrm{Ng} \mathrm{JM}$, Jennings PE, Laboi $P$ and Jayagopal V. Erythropoetin treatment significantly alters measured glycated haemoglobin (HbA1c). Diabetic Medicine 2008; 25:239-240.

10. Kim MK, Kwon HS, Baek KH, Lee JH, Park WC, Sohn HS, et al. Effects of thyroid hormone on $\mathrm{A} 1 \mathrm{C}$ and glycated albumin levels in nondiabetic subjects with overt hypothyroidism. Diabetes Care 2010; 33:2546-2548.

11. Christy AL, Manjrekar P, Babu RP, M S R and Hegde A. Elevation of $\mathrm{HbA} 1 \mathrm{C}$ in non-diabetic hypothyroid individuals: is anaemia the connecting link? - A preliminary study. J Clin Diagn Res 2013; 7(11):2442-2444.

12. Bilic-Komarica E, Beciragic A and Junuzovi D.The Importance of $\mathrm{HbA1c}$ Control in Patients with Subclinical Hypothyroidism Mat Soc Med 2012; 24(4):212-219.

13. Anantarapu S, Vaikkakara S, Sachan A, Venkata BP, Suchitra MM, Reddy AP, et al. Effects of thyroid hormone replacement on glycated hemoglobin levels in non diabetic subjects with overt hypothyroidism. The Archives of Endocrinolology \& Metabolism 2015; 59:495-500.

\footnotetext{
Authors Contribution:

AS and PK - Concept and design of the study, definition of intellectual content, literature search, clinical studies, experimental studies, data acquisition and analysis, manuscript preparation and final approval.
}

Source of Support: Nil, Conflict of Interest: None declared. 